\title{
Combined impacts of multimorbidity and mental disorders on frequent emergency department visits: a retrospective cohort study in Quebec, Canada
}

\author{
Myles Gaulin BA, Marc Simard MSc, Bernard Candas PhD, Alain Lesage MD MPhil, Caroline Sirois BPharm PhD
}

Cite as: CMAJ 2019 July 2;191:E724-32. doi: 10.1503/cmaj.181712

See related article at www.cmaj.ca/lookup/doi/10.1503/cmaj.190709

\section{ABSTRACT \\ BACKGROUND: Multimorbidity and men- tal disorders are independently associ- ated with frequent visits to the emer- gency department ( $\geq 3$ visits/yr), but their interaction has been little studied. We aimed to measure the interaction between mental disorders and physical multimorbidity with respect to frequent visits to the emergency department.}

METHODS: We conducted a populationbased cohort study of adults in Quebec from 2012 to 2016, using the Quebec Integrated Chronic Disease Surveillance System. We assessed multimorbidity as the number of physical illnesses and mental disorders as serious (psychotic or bipolar disorders), common or absent, using data from 2012 to 2014 . We counted emergency department visits from 2014 to 2015 . We used logistic regression to estimate interaction on frequent visits to the emergency department from 2 perspectives: of public health (additive scale as differences in risk) and of individual patients (multiplicative scale as odds ratios).

RESULTS: Each additional physical illness was associated with a greater increase in the absolute risk of frequent visits to the emergency department for people with mental disorders. Between 0 and $\geq 4$ physical conditions, the absolute risk increased more for individuals with serious mental disorders (16.2\%) than common (15.3\%) or no disorders (11.4\%).
On the relative scale, for people with no mental disorders and $\geq 4$ physical conditions, odds of frequent visits to the emergency department were 6.2 (95\% confidence interval $[\mathrm{Cl}] 6.08-6.35)$ times the odds for people with no physical conditions. For individuals with common and serious mental illnesses, corresponding odds ratios were 4.75 (95\% $\mathrm{Cl} 4.60-4.90)$ and 3.7 (95\% Cl 3.18-3.57), respectively.

INTERPRETATION: Mental disorders interact with physical multimorbidity to increase the odds of frequent visits to the emergency department. More research is needed on interventions that promote high-quality care for mental illness, especially in the context of physical multimorbidity.
M ultimorbidity, the co-occurrence of multiple chronic illnesses, has increased in prevalence as populations age and improved medical treatment extends the lives of patients with chronic illness. ${ }^{1,2}$ Mental disorders affect as many as $30 \%$ of people with multimorbidity. ${ }^{1}$ Mental disorders are also associated with more severe physical illness, including increased symptom burden, shortened lifespan and compounded disability. ${ }^{3,4}$ Both physical multimorbidity and mental disorders are growing individual and public-health burdens, associated with disability, mortality and use of primary care services. ${ }^{1,3,5,6}$
Treatment for patients with multimorbidity is complex and may be less effective if care for each condition is planned in isolation. ${ }^{1,2}$ Gaps in care may lead to potentially preventable visits to the emergency department to treat exacerbations or complications of chronic illness, including mental disorders. ${ }^{7-16}$ Although the independent effects of physical illnesses and mental disorders on frequent emergency department visits are known, their combined effect (also called synergy or interaction) has not been well studied. However, such synergy has been observed with work-related disability, for which people with mental and physical disorders have a disproportionately greater risk. ${ }^{6}$ The 
presence of synergy between physical illnesses and mental disorders would suggest that better treatment for patients with mental disorders may have a twofold impact on frequent emergency department visits by reducing the direct impact of mental disorders and the impact of synergy with physical conditions.

The primary objective of the study was to determine whether and how much physical multimorbidity and mental disorders interact with respect to frequent emergency department visits. The size of this potential synergy depends on the perspective of interpretation: a small increase in risk for a large number of patients may have large public health effects, while a large increase for a small number may have little impact on public health. ${ }^{17}$ We thus examined interaction from both public health (additive scale) and patient perspectives (multiplicative scale). ${ }^{18}$ Our secondary objective was to estimate the number of emergency department visits owing to the separate and joint effects of physical multimorbidity and mental disorders.

\section{Methods}

\section{Study population and data source}

We conducted a population-based cohort study of adults in Quebec, Canada, using the Quebec Integrated Chronic Disease Surveillance System (QICDSS). ${ }^{19}$ The QICDSS links demographic data, the death registry, physician claims and hospital discharge records starting from Jan. 1, 1996. Quebec has universal-access health care services with free-of-charge hospital stays and medical care, allowing the QICDSS to cover $98 \%$ of the provincial adult population. ${ }^{19}$ Demographic data include place of residence, age, sex and neighbourhood-level Pampalon index scores for social deprivation (proportion of single-parent families and individuals living alone) and material deprivation (employment, educational attainment and income). ${ }^{20}$ Physician claims include diagnoses coded using the International Classification of Disease, 9th Revision, Quebec adaptation (ICD-9-QC). Hospital discharge records include the admission diagnosis, primary diagnosis and up to 25 secondary diagnoses coded using the ICD 10th Revision Canadian Coding Standard (ICD-10-CA). Using previously validated case definitions, diseases can be identified using these codes with good reliability and sensitivity. ${ }^{19,21-27}$ We excluded deceased patients, as end-of-life health care use is unrepresentative of the general population. ${ }^{28}$ We also excluded people in longterm care facilities, for whom physician claims are unavailable.

\section{Variables}

\section{Physical multimorbidity}

We measured physical multimorbidity from Apr. 1, 2012, to Mar. 31, 2014, using unweighted and weighted counts of the 27 physical conditions of the Combined Comorbidity Index, previously validated with the QICDSS. ${ }^{29}$ We excluded gestational hypertension and gestational diabetes (Appendix 1, available at www.cmaj.ca/lookup/suppl/doi:10.1503/cmaj.181712/-/DC1). We used validated case definitions of 1 inpatient or 2 outpatient diagnostic codes at least 30 days apart within 2 years. ${ }^{30}$ The unweighted count used the number of diseases present $(0,1,2$,
$3, \geq 4)$. The weighted physical multimorbidity score $(0,1,2-3$, $4-5, \geq 6$ ) used the sum of Combined Comorbidity Index disease weights derived by Charlson's method, where weights indicate strength of association with mortality. ${ }^{29}$

\section{Mental disorders}

We documented mental disorders from Apr. 1, 2013, to Mar. 31, 2014. We included all ICD-9 and ICD-10 mental disorders (Appendix 1) and used a case definition of 1 inpatient or outpatient claim within 1 year. This shorter window reduces misclassification from the remitting, relapsing course of many mental disorders. Mental disorders were categorized as serious or common, according to a literature-based definition accounting for the greater average disability associated with serious disorders. , $31,32^{-3}$ Serious mental disorders included schizophrenia and schizoaffective disorders, bipolar and manic disorders, and other psychotic disorders. Common mental disorders included all other diagnoses.

\section{Frequent visits to the emergency department}

A single visit to the emergency department was defined as 1 or more emergency department-related claims on up to 2 consecutive days. ${ }^{33}$ There is no standard threshold for frequent emergency department visits, although 3 and 4 are the most common. ${ }^{34}$ We thus defined our threshold using Quebec utilization rates, as 3 or more visits (95th percentile) between Apr. 1, 2014, and Mar. 31, 2015.

\section{Covariates}

Covariates included sex, age, Pampalon index and rurality. We defined rural communities as those with fewer than 10000 residents. ${ }^{35}$

\section{Statistical analysis}

We calculated descriptive statistics for the study population according to emergency department visits (nonfrequent, $\leq 2 / \mathrm{yr}$; frequent, $\geq 3 / y r$ ). We measured interaction or potential synergy between mental disorders and physical multimorbidity with respect to frequent visits to the emergency department using a logistic regression model that incorporated physical multimorbidity, mental disorders, physical multimorbidity by mental disorder interaction, and all covariates. We verified multicollinearity between all variables. Synergy was evaluated in terms of public health impact (absolute increase) and patient impact (relative increase).

\section{Public health impact}

We measured public health impact of mental disorders and physical multimorbidity on the absolute scale, which is preferred for questions of public health, as it provides information about the total number of additional cases attributable to a risk factor. ${ }^{17}$ We compared differences in the adjusted proportions of frequent users of the emergency department between individuals with no physical conditions and with 4 or more physical conditions, across mental disorder statuses. We estimated adjusted proportions using the prediction at the mean method. ${ }^{36}$ Synergy between mental disorders and physical multimorbidity is 
Table 1 (part 1 of 2): Characteristics of adult (> $18 \mathrm{yr}$ ) population, nonfrequent and frequent users of the emergency

department in Quebec, fiscal year 2014/15

\begin{tabular}{|c|c|c|c|c|c|}
\hline Characteristics & $\begin{array}{c}\text { Total study } \\
\text { population, } n(\%)^{\star}\end{array}$ & $\begin{array}{l}\text { Nonfrequent } \dagger \\
\text { ED users, } n(\%)^{\star}\end{array}$ & $\begin{array}{c}\text { Frequent } \ddagger \\
\text { ED users, } n(\%)^{\star}\end{array}$ & $\begin{array}{l}\text { Standard } \\
\text { difference§ }\end{array}$ & $p$ value \\
\hline Population size & $5316832(100)$ & 5102911 (96) & $213921(4)$ & & \\
\hline ED admissions (median) & $2204454(0)$ & $1294317(0)$ & $910137(3)$ & & \\
\hline Age, yr, mean $\pm S D$ & $51.2 \pm 17.93$ & $51.0 \pm 17.8$ & $54.4 \pm 20.4$ & 0.18 & $<0.0001$ ฯ \\
\hline \multicolumn{6}{|l|}{ Age group, yr } \\
\hline $18-24$ & $486288(9.2)$ & $466562(9.1)$ & $19726(8.2)$ & 0.01 & \\
\hline $25-34$ & 702982 (13.2) & $674738(13.2)$ & $28244(13.2)$ & 0.00 & \\
\hline $35-44$ & 787369 (14.8) & 760970 (14.9) & $26399(12.3)$ & -0.22 & \\
\hline $45-54$ & $1011673(19.0)$ & 979209 (19.2) & 32464 (15.2) & -0.28 & \\
\hline $55-64$ & $1056480(19.9)$ & $1022168(20.0)$ & $34312(16.0)$ & -0.27 & \\
\hline $65-74$ & 753395 (14.2) & $721422(14.1)$ & $31973(15.0)$ & 0.07 & \\
\hline $75-84$ & $384081(7.2)$ & $357253(7.0)$ & $26828(12.5)$ & 0.63 & \\
\hline$\geq 85$ & $134564(2.5)$ & $120589(2.4)$ & $13975(6.5)$ & 0.97 & $<0.0001^{\star \star}$ \\
\hline \multicolumn{6}{|l|}{ Sex } \\
\hline Male & 2539865 (47.8) & $2446263(47.9)$ & $93602(43.8)$ & -0.17 & \\
\hline Female & 2776967 (52.2) & $2656648(52.1)$ & $120319(56.2)$ & 0.17 & $<0.0001^{\star \star}$ \\
\hline \multicolumn{6}{|l|}{ Location } \\
\hline Nonrural & $4207827(79.7)$ & $4057454(80.0)$ & $150373(70.6)$ & -0.51 & \\
\hline Rural & $1074234(20.3)$ & $1011587(20.0)$ & $62647(29.4)$ & 0.51 & $<0.0001^{\star \star}$ \\
\hline Missing data & 34771 & 33870 & 901 & & \\
\hline \multicolumn{6}{|l|}{ Material deprivation } \\
\hline 1 (least deprived) & 998753 (19.8) & $972823(20.1)$ & $25930(13.1)$ & -0.51 & \\
\hline 2 & $1028192(20.4)$ & 995089 (20.5) & $33103(16.7)$ & -0.25 & \\
\hline 3 & $1020225(20.2)$ & $981557(20.2)$ & $38668(19.5)$ & -0.04 & \\
\hline 4 & $1024684(20.3)$ & 978698 (20.2) & $45986(23.2)$ & 0.18 & \\
\hline 5 (most deprived) & $975786(19.3)$ & 920894 (19.0) & $54892(27.6)$ & 0.49 & $<0.0001^{\star *}$ \\
\hline Missing data & 269192 & 253850 & 15342 & & \\
\hline \multicolumn{6}{|l|}{ Social deprivation } \\
\hline 1 (least deprived) & $1005149(19.9)$ & $970250(20.0)$ & 34899 (17.6) & -0.16 & \\
\hline 2 & $1027120(20.4)$ & $988500(20.4)$ & $38620(19.5)$ & -0.06 & \\
\hline 3 & 1040014 (20.6) & 1000407 (20.6) & $39607(20.0)$ & -0.04 & \\
\hline 4 & $1002699(19.9)$ & 961984 (19.8) & 40715 (20.5) & 0.04 & \\
\hline 5 (most deprived) & 972658 (19.3) & 927920 (19.1) & $44738(22.5)$ & 0.21 & $<0.0001^{\star \star}$ \\
\hline Missing data & 269192 & 253850 & 15342 & & \\
\hline \multicolumn{6}{|l|}{ Physical multimorbidity } \\
\hline Absent & 4900550 (92.2) & 4734861 (92.8) & 165689 (77.5) & -1.27 & \\
\hline Present & $416282(7.8)$ & $368050(7.2)$ & $48232(22.5)$ & 1.27 & $<0.0001^{\star \star}$ \\
\hline $\begin{array}{l}\text { No. of physical conditions, mean } \\
\pm \text { SD }\end{array}$ & $0.42 \pm 1.0$ & $0.39 \pm 1.0$ & $1.10 \pm 2.0$ & 0.46 & $<0.0001^{\star \star}$ \\
\hline \multicolumn{6}{|l|}{ No. of physical conditions } \\
\hline 0 & 4016066 (75.5) & 3891864 (76.3) & 124202 (58.1) & -0.86 & \\
\hline 1 & 884484 (16.6) & 842997 (16.5) & $41487(19.4)$ & 0.20 & \\
\hline 2 & $213618(4.0)$ & $197075(3.9)$ & $16543(7.7)$ & 0.70 & \\
\hline 3 & 83013 (1.6) & $73618(1.4)$ & $9395(4.4)$ & 1.07 & \\
\hline$\geq 4$ & $119651(2.2)$ & $97357(1.9)$ & 22294 (10.4) & 1.52 & $<0.0001^{\star \star}$ \\
\hline
\end{tabular}


Table 1 (part 2 of 2): Characteristics of adult (> $18 \mathrm{yr}$ ) population, nonfrequent and frequent users of the emergency

department in Quebec, fiscal year 2014/15

\begin{tabular}{|c|c|c|c|c|c|}
\hline Characteristic & $\begin{array}{c}\text { Total study } \\
\text { population, } n(\%)^{\star}\end{array}$ & $\begin{array}{l}\text { Nonfrequent } \dagger \\
\text { ED users, } n(\%)^{\star}\end{array}$ & $\begin{array}{c}\text { Frequent } \neq \\
\text { ED users, } n(\%)^{\star}\end{array}$ & $\begin{array}{l}\text { Standard } \\
\text { difference§ }\end{array}$ & $p$ value \\
\hline \multicolumn{6}{|c|}{ Mental disorder status } \\
\hline None & $4638633(87.2)$ & $4479712(87.8)$ & $158921(74.3)$ & -0.91 & \\
\hline Common & $598276(11.3)$ & $554086(10.9)$ & $44190(20.7)$ & 0.75 & \\
\hline Serious & 79923 (1.5) & $69113(1.4)$ & $10810(5.1)$ & 1.19 & $<0.00019$ \\
\hline \multicolumn{6}{|c|}{$\begin{array}{l}\text { Note: } E D=\text { emergency department, } S D=\text { standard deviation. } \\
\text { *Unless otherwise specified. } \\
\text { tNonfrequent is defined as } 0-2 \text { visits per year. } \\
\text { tFrequent is defined as } \geq 3 \text { visits per year. } \\
\text { §Absolute standard differences } \leq 0.10 \text { are interpreted as no difference between groups. } \\
\text { ฯ Student } t \text { test. }\end{array}$} \\
\hline
\end{tabular}

observed when the proportion of frequent users of the emergency department among individuals with mental disorders and physical multimorbidity is greater than the sum of proportions among individuals with only physical conditions and only mental disorders. ${ }^{6,17}$ We illustrated synergy graphically by evaluating whether change in adjusted proportions of frequent users of the emergency department for each additional physical condition differed across mental disorder statuses. Nonparallel curves indicate synergy. We also evaluated synergy using confidence intervals of the relative excess risk from interaction statistic, which is positive when synergy exists. We also estimated numbers of visits owing to physical multimorbidity, mental disorders and synergy. ${ }^{17}$ Using the observed adjusted proportions, we estimated the proportion owing to synergy at each combination of physical multimorbidity and mental disorders using the formula $p=\mathrm{P}_{\mathrm{b}}+$ $P_{p}+P_{m}+P_{s}$, where $P$ is the observed proportion, $P_{b}$ is the background proportion, $P_{p}$ is the proportion owing to physical multimorbidity alone, $\mathrm{P}_{\mathrm{m}}$ is the proportion owing to mental disorders alone and $\mathrm{P}_{\mathrm{s}}$ is the proportion owing to synergy (Appendix 2, available at www.cmaj.ca/lookup/suppl/doi:10.1503/ cmaj.181712/-/DC1). We then multiplied these adjusted proportions by the observed number of visits within each combination of physical multimorbidity and mental disorders.

\section{Patient impact}

We measured patient impact of each additional physical condition separately by mental disorder status, by calculating increase in odds of frequent visits to the emergency department relative to status-specific baselines. We used odds ratios (ORs) equivalent to the odds of frequent emergency department visits at each number of physical conditions divided by the odds at 0 physical conditions. Ratios were calculated from regression coefficients for physical multimorbidity-mental disorder interaction terms. A significant interaction term coefficient indicates that relative increase of frequent visits to the emergency department with 1 additional physical condition differs by mental disorder status.

We conducted sensitivity analyses using the same approach with the Combined Comorbidity Index score to examine whether interaction differed when using this weighted measure.
All statistical tests were 2-sided, with significance level of $p<0.05$. Analyses were performed using SAS 9.4 (SAS Institute, Cary, NC).

\section{Ethics approval}

The use of QICDSS for the surveillance of chronic diseases has been approved by government bodies, the Public Health Ethics Committee and the Commission d'accès à l'information du Québec.

\section{Results}

From an initial cohort of 5741367 people, 5316832 (Table 1) met inclusion criteria (Appendix 3, available at www.cmaj.ca/lookup/ suppl/doi:10.1503/cmaj.181712/-/DC1). Frequent users of the emergency department represented $4.0 \%$ of the population and accounted for $41.3 \%$ of emergency department visits. The population was $52.2 \%$ female and $47.8 \%$ male. The mean age was 51.2 years. Three-quarters $(75.5 \%)$ had no physical conditions and $7.8 \%$ had 2 or more. Mental disorders affected $12.8 \% ; 11.3 \%$ had common and $1.5 \%$ had serious mental disorders. Frequent users of the emergency department were older, more likely to be women, and more socially and materially deprived.

Both physical multimorbidity and mental disorders were associated with frequent visits to the emergency department (Table 2). Compared with those without physical conditions or mental disorders, 1 condition increased odds of frequent emergency department visits by $60 \%$ (OR 1.60, 95\% confidence interval $[\mathrm{Cl}] 1.58-1.62)$. Odds increased monotonically; individuals affected by 4 or more physical conditions had more than 6 times the odds (OR 6.21, 95\% Cl 6.08-6.35). Common mental disorders alone resulted in twice the odds (OR $2.08,95 \% \mathrm{Cl} 2.04-2.11$ ) of frequent visits, while serious mental disorders alone resulted in nearly 4 times the odds (OR 3.88, 95\% Cl 3.76-4.00) compared with individuals without mental disorders or physical conditions.

\section{Public health impact}

We found a potential synergistic impact of mental disorders and physical multimorbidity on emergency department visits on the additive scale (Figure 1). Between 0 and 4 or more physical 
Table 2: Crude proportion and crude and adjusted ORs of frequent users of the emergency department in Quebec, fiscal year 2014/15

\begin{tabular}{|c|c|c|c|}
\hline Characteristics* & $\begin{array}{l}\text { Frequent ED users, } n(\%) \\
\qquad n=213921\end{array}$ & $\begin{array}{l}\text { Unadjusted ORs } \\
\qquad(95 \% \mathrm{Cl}) \dagger\end{array}$ & $\begin{array}{l}\text { Adjusted ORs } \ddagger \\
\qquad(95 \% \mathrm{Cl}) \dagger\end{array}$ \\
\hline \multicolumn{4}{|l|}{ Age group, yr } \\
\hline $18-24$ & $19726(4.1)$ & 1.00 (Ref.) & 1.00 (Ref.) \\
\hline $25-34$ & $28244(4.0)$ & $0.99(0.97-1.01)$ & $0.88(0.86-0.89)$ \\
\hline $35-44$ & 26399 (3.4) & $0.82(0.81-0.84)$ & $0.70(0.69-0.71)$ \\
\hline $45-54$ & 32464 (3.2) & $0.78(0.77-0.80)$ & $0.62(0.61-0.63)$ \\
\hline $55-64$ & $34312(3.3)$ & $0.79(0.78-0.81)$ & $0.56(0.55-0.57)$ \\
\hline $65-74$ & $31973(4.2)$ & $1.05(1.03-1.07)$ & $0.62(0.61-0.63)$ \\
\hline $75-84$ & $26828(7.0)$ & $1.78(1.74-1.81)$ & $0.83(0.81-0.85)$ \\
\hline $85+$ & $13975(10.4)$ & $2.74(2.68-2.80)$ & $1.06(1.03-1.08)$ \\
\hline \multicolumn{4}{|l|}{ Sex } \\
\hline Male & $93602(3.7)$ & 1.00 (Ref.) & 1.00 (Ref.) \\
\hline Female & $120319(4.3)$ & $1.18(1.17-1.19)$ & $1.12(1.11-1.13)$ \\
\hline \multicolumn{4}{|l|}{ Location } \\
\hline Nonrural & 151098 (3.6) & 1.00 (Ref.) & 1.00 (Ref.) \\
\hline Rural & $62823(5.9)$ & $1.68(1.67-1.70)$ & $1.66(1.64-1.68)$ \\
\hline \multicolumn{4}{|l|}{ Material deprivation } \\
\hline 1 (least deprived) & 25930 (2.6) & 1.00 (Ref.) & 1.00 (Ref.) \\
\hline 2 & $33103(3.2)$ & $1.25(1.23-1.27)$ & $1.20(1.18-1.22)$ \\
\hline 3 & $38668(3.8)$ & $1.48(1.46-1.50)$ & $1.33(1.30-1.35)$ \\
\hline 4 & $45986(4.5)$ & $1.76(1.74-1.79)$ & $1.47(1.45-1.49)$ \\
\hline 5 (most deprived) & $54892(5.6)$ & $2.24(2.20-2.27)$ & $1.74(1.72-1.77)$ \\
\hline \multicolumn{4}{|l|}{ Social deprivation } \\
\hline 1 (least deprived) & 34899 (3.5) & 1.00 (Ref.) & 1.00 (Ref.) \\
\hline 2 & 38620 (3.8) & $1.09(1.07-1.10)$ & $1.03(1.02-1.05)$ \\
\hline 3 & 39607 (3.8) & $1.10(1.09-1.12)$ & $1.06(1.05-1.08)$ \\
\hline 4 & 40715 (4.1) & $1.18(1.16-1.19)$ & $1.17(1.15-1.19)$ \\
\hline 5 (most deprived) & $44738(4.6)$ & $1.34(1.32-1.36)$ & $1.36(1.34-1.38)$ \\
\hline \multicolumn{4}{|l|}{ No mental disorder } \\
\hline 0 physical condition & $96581(2.7)$ & 1.00 (Ref.) & 1.00 (Ref.) \\
\hline 1 physical condition & $31438(4.1)$ & $1.52(1.50-1.54)$ & $1.60(1.58-1.62)$ \\
\hline 2 physical conditions & $11703(6.6)$ & $2.54(2.49-2.59)$ & $2.60(2.54-2.65)$ \\
\hline 3 physical conditions & $6192(9.7)$ & $3.85(3.75-3.95)$ & $3.80(3.69-3.91)$ \\
\hline $4+$ physical conditions & $13007(15.8)$ & $6.73(6.59-6.86)$ & $6.21(6.08-6.35)$ \\
\hline \multicolumn{4}{|l|}{ Common mental disorders } \\
\hline 0 physical conditions & $22990(5.5)$ & $2.07(2.04-2.10)$ & $2.08(2.04-2.11)$ \\
\hline 1 physical conditions & $8072(7.9)$ & $3.08(3.01-3.16)$ & $3.15(3.07-3.22)$ \\
\hline 2 physical conditions & $3759(12.0)$ & $4.88(4.71-5.05)$ & $4.81(4.64-4.98)$ \\
\hline 3 physical conditions & $2427(15.6)$ & $6.60(6.32-6.89)$ & $6.28(6.00-6.56)$ \\
\hline $4+$ physical conditions & $6952(23.7)$ & $11.08(10.77-11.39)$ & $9.86(9.57-10.15)$ \\
\hline \multicolumn{4}{|l|}{ Serious mental disorders } \\
\hline 0 physical conditions & $4631(9.7)$ & $3.86(3.74-3.98)$ & $3.88(3.76-4.00)$ \\
\hline 1 physical conditions & $1977(13.6)$ & $5.63(5.37-5.91)$ & $5.73(5.46-6.02)$ \\
\hline 2 physical conditions & $1081(18.2)$ & $7.94(7.43-8.48)$ & $7.92(7.41-8.47)$ \\
\hline 3 physical conditions & $776(20.7)$ & $9.32(8.61-10.09)$ & $9.02(8.32-9.77)$ \\
\hline $4+$ physical conditions & $2345(28.6)$ & $14.32(13.64-15.03)$ & $13.07(12.44-13.74)$ \\
\hline
\end{tabular}


A

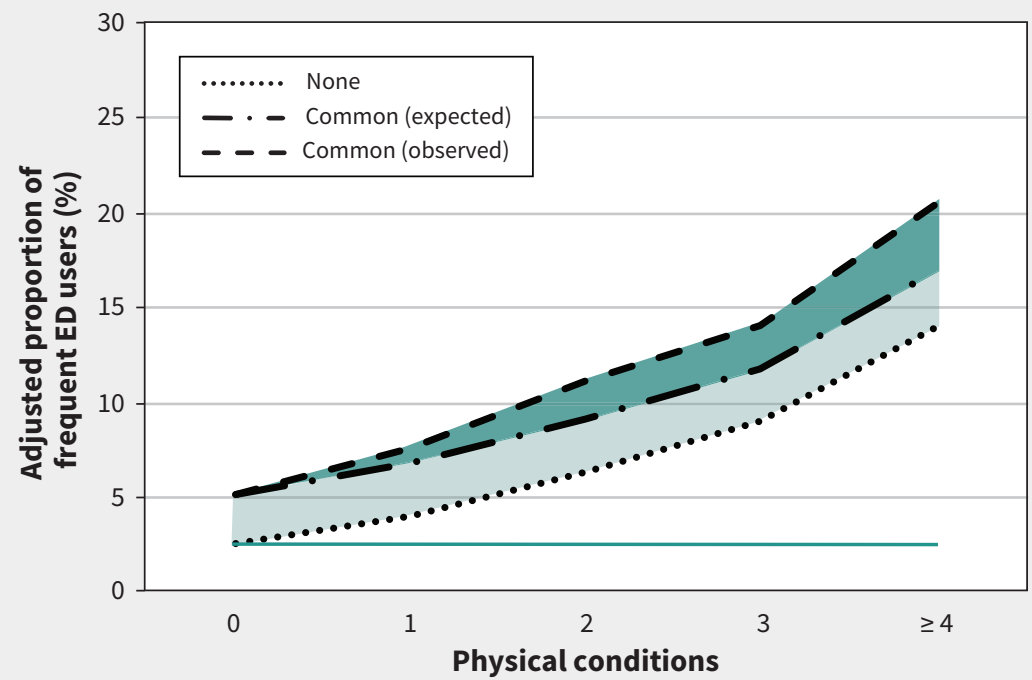

\begin{tabular}{lccccc} 
& 0 & 1 & 2 & 3 & $\geq 4$ \\
\hline No mental & $2.5 \%$ & $4.0 \%$ & $6.3 \%$ & $9.0 \%$ & $13.9 \%$ \\
disorder & $(2.5-2.6)$ & $(4.0-4.0)$ & $(6.2-6.4)$ & $(8.8-9.2)$ & $(13.7-14.2)$ \\
& & & & & \\
Common mental & $5.1 \%$ & $7.6 \%$ & $11.1 \%$ & $14 \%$ & $20.4 \%$ \\
disorders & $(5.1-5.2)$ & $(7.4-7.7)$ & $(10.8-11.5)$ & $(13.5-14.6)$ & $(20.0-20.9)$ \\
\hline
\end{tabular}

B

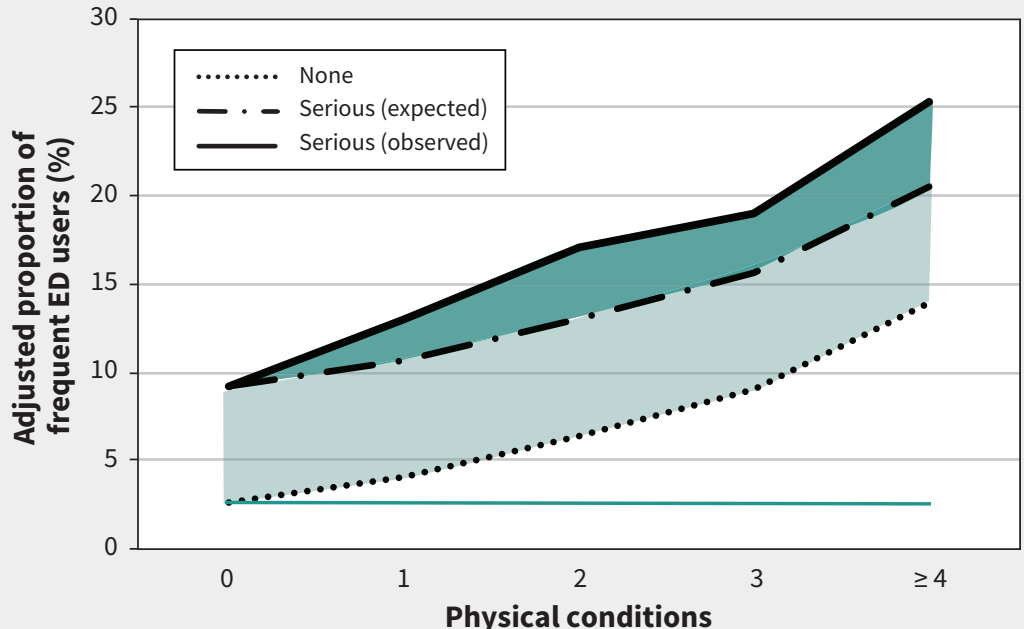

\begin{tabular}{lccccc} 
& 0 & 1 & 2 & 3 & $\geq 4$ \\
\hline No mental & $2.5 \%$ & $4.0 \%$ & $6.3 \%$ & $9.0 \%$ & $13.9 \%$ \\
disorder & $(2.5-2.6)$ & $(4.0-4.0)$ & $(6.2-6.4)$ & $(8.8-9.2)$ & $(13.7-14.2)$ \\
& & $13.0 \%$ & $17.1 \%$ & $19.0 \%$ & $25.4 \%$ \\
Serious mental & $9.2 \%$ & $(12.5-13.5)$ & $(16.2-18.0)$ & $(17.8-20.3)$ & $(24.5-26.3)$ \\
disorders & $(8.9-9.4)$ &
\end{tabular}

Figure 1: Public health impact (absolute scale). Adjusted* proportions of frequent users of the emergency department (ED) ( $\geq 3$ admissions/yr) by number of physical conditions in Quebec, stratified by mental disorder status, fiscal year 2014/15. (A) Adjusted proportions (95\% confidence interval [CI]) of frequent ED users with common mental disorders $(n=598276)$, versus no mental disorder $(n=4638633)$. (B) Adjusted proportions (95\% Cl) of frequent ED users with serious mental disorders $(n=79$ 923), versus no mental disorder $(n=4638633)$. *Proportions adjusted for age, sex, material deprivation, social deprivation and rurality. The solid, lowermost line represents the base proportion admitted with neither mental nor physical illnesses. The bottom, dotted curve represents proportions of frequent ED users with no mental disorder. The middle, dotted and dashed curve represents the expected proportion estimated from simple addition of effects of physical multimorbidity and mental disorders. The topmost, dashed curve corresponds to the actual observed proportions. The light teal area corresponds to frequent admissions from mental disorders, and the dark teal area corresponds to the excess ED admissions owing to synergy. 
conditions, frequent emergency department visits increased more for those with serious mental disorders (16.2\%) than for those with common mental disorders (15.3\%) or no mental disorders (11.4\%). Nonparallel trends, with increased slopes associated with mental disorders, indicate this synergy graphically. All statistics for relative excess risk due to interaction (not shown) corroborated graphical evidence of synergy. The dark teal area in Figure $1 \mathrm{~A}$ represents the difference between the adjusted proportions expected from simple addition of effects and the observed adjusted proportions and illustrates synergy between common mental disorders and physical conditions.

Table 3 presents results from statistical modelling showing that for people with common mental disorders, visits resulting from physical multimorbidity ranged from $19.4 \%$ to $55.8 \%$ of the total, and increased with the number of physical conditions. Visits owing to mental disorders accounted for an estimated $34.2 \%$ in the absence of physical conditions and $12.7 \%$ with 4 or more physical conditions. Synergy accounted for an estimated $13.0 \%-19.9 \%$ of visits. For those with serious mental disorders, physical multimorbidity accounted for $11.3 \%-44.8 \%$ of visits. Mental disorders accounted for a larger percentage, from $26.1 \%$ to $51.0 \%$. Synergy also explained a greater proportion, from $17.8 \%$ to $24.3 \%$. In total, mental disorders and physical condition-mental disorder synergy is estimated to account for as many as 128752 visits (5.8\% of all Quebec visits), of which 24388 could be attributed to synergy.

\section{Patient impact}

Relative increases in risk of frequent emergency department visits per additional physical condition by mental disorder status are presented in Appendix 4 (available at www.cmaj.ca/lookup/ suppl/doi:10.1503/cmaj.181712/-/DC1). Relative increases in odds of frequent emergency department visits with each additional physical condition were higher for individuals without mental disorders (OR for $\geq 4$ physical conditions $6.21,95 \% \mathrm{Cl}$ 6.08-6.35) than those with common (OR for $\geq 4$ physical conditions $4.75,95 \% \mathrm{Cl} 4.60-4.90$ ) or serious mental disorders (OR for $\geq 4$ physical conditions $3.37,95 \% \mathrm{Cl} 3.18-3.57$ ) (Appendix 4). The smaller relative increase for individuals with mental disorders is observed because frequent emergency department visits in the absence of physical conditions are already more common among those with serious mental disorders (9.2\%) than those with common $(5.1 \%)$ or no $(2.5 \%)$ mental disorders (Figure 1 ).

\section{Sensitivity analysis}

We obtained similar results with a weighted physical multimorbidity score. However, model fit and calibration were poorer (Appendix 5, available at www.cmaj.ca/lookup/suppl/doi:10.1503/ cmaj.181712/-/DC1).

\section{Interpretation}

In this population-based study, we showed that physical multimorbidity and mental disorders are each associated with frequent emergency department visits and the potential synergy between physical multimorbidity and mental disorders significantly increases total impact on public health. For individuals, the relative impact of physical multimorbidity is less important when mental disorders are present, as mental disorders themselves

Table 3: No. and proportion of emergency department admissions resulting from physical multimorbidity, mental disorders and potential synergy in Quebec, stratified by mental disorder status, fiscal year 2014/15

\begin{tabular}{|c|c|c|c|c|c|}
\hline \multirow[b]{2}{*}{ Characteristics } & \multicolumn{5}{|c|}{$\begin{array}{l}\text { No. of physical conditions } \\
\qquad N=678199\end{array}$} \\
\hline & $0, n(\%)$ & $1, n(\%)$ & $2, n(\%)$ & $3, n(\%)$ & $\geq 4, n(\%)$ \\
\hline \multicolumn{6}{|l|}{ Common mental disorders } \\
\hline Admissions owing to synergy & $0(0.0)$ & $4790(13.0)$ & 3644 (19.9) & $2096(17.5)$ & $6991(19.1)$ \\
\hline $\begin{array}{l}\text { Admissions owing to mental } \\
\text { disorders }\end{array}$ & $50733(50.5)$ & $12610(34.2)$ & $4266(23.3)$ & $2208(18.4)$ & $4628(12.7)$ \\
\hline $\begin{array}{l}\text { Admissions owing to physical } \\
\text { multimorbidity }\end{array}$ & $0(0.0)$ & $7147(19.4)$ & $6242(34.0)$ & $5515(46.0)$ & $20366(55.8)$ \\
\hline Base & $49751(49.5)$ & $12366(33.5)$ & $4184(22.8)$ & $2165(18.1)$ & $4539(12.4)$ \\
\hline Total admissions & $100484(100.0)$ & $36914(100.0)$ & $18336(100.0)$ & $11984(100.0)$ & $36524(100.0)$ \\
\hline \multicolumn{6}{|l|}{ Serious mental disorders } \\
\hline Admissions owing to synergy & $0(0.0)$ & $1970(18.2)$ & $1490(24.3)$ & $784(17.8)$ & $2622(19.1)$ \\
\hline $\begin{array}{l}\text { Admissions owing to mental } \\
\text { disorders }\end{array}$ & $16889(72.3)$ & $5529(51.0)$ & $2382(38.8)$ & $1531(34.8)$ & $3588(26.1)$ \\
\hline $\begin{array}{l}\text { Admissions owing to physical } \\
\text { multimorbidity }\end{array}$ & $0(0.0)$ & $1223(11.3)$ & $1360(22.1)$ & $1493(34.0)$ & $6164(44.8)$ \\
\hline Base & $6467(27.7)$ & $2117(19.5)$ & $912(14.8)$ & $586(13.3)$ & $1374(10.0)$ \\
\hline Total admissions & $23356(100.0)$ & $10839(100.0)$ & $6114(100.0)$ & $4394(100.0)$ & $13748(100.0)$ \\
\hline
\end{tabular}


confer a high increased risk of visits to the emergency department. For individuals, the effect of physical multimorbidity is overshadowed by that of mental disorders.

These findings align with previous evidence on the physical health effects of mental disorders. Previous research showed independent associations between frequent visits to the emergency department and physical multimorbidity ${ }^{7,9-12}$ or mental disorders. ${ }^{10,11,13-16,37}$ These studies did not distinguish common and serious mental disorders. However, the greater effect of serious mental disorders is consistent with the greater functional disability associated with psychotic and bipolar disorders. ${ }^{4}$ The synergy we found also comports with the synergistic effect of physical multimorbidity and mental disorders on functional disability. ${ }^{6}$ As frequent visits to the emergency department correlate with disability, ${ }^{13}$ our results converge with existing evidence.

Previous research offers numerous potential explanations for synergy between mental disorders and physical illnesses. People with mental disorders may engage in more unhealthy behaviours, such as tobacco use and poor dietary habits, and may have difficulty adhering to treatment. ${ }^{3,38,39}$ Consistency and quality of care may also be implicated. Health care systems are specialized for individual conditions and may provide fragmented care for physical multimorbidity. ${ }^{2}$ Such fragmentation may have a greater impact on physical-mental multimorbidity. For instance, although rates of death and hospital admission for circulatory diseases were greater for people with mental disorders, rates of specialist procedures for these diseases were lower, because people with mental disorders receive less proactive treatment. ${ }^{40}$ Other studies imply negative perceptions of people with mental disorders as noncompliant or difficult-to-treat patients. ${ }^{38,41}$ Some mental disorders share common causal pathways with other chronic diseases. Genetic vulnerabilities may lead to overreactivity of endocrine and immune processes to psychosocial stressors, or allostatic load which, over time, may lead to depression and organ damage, increasing vulnerability to chronic disease. ${ }^{42,43}$ Given this synergy, innovative health care models may have impact beyond the expected effect, reducing the number of emergency department visits that result from both factors. One such model involves the use of clinical case managers in emergency departments to connect patients to nonemergent care providers. ${ }^{48}$ Such an approach could promote coherent care trajectories and has the potential to prevent up to $6 \%$ of emergency department visits across the Quebec population, based on the findings from our study.

\section{Limitations}

We note several limitations. The QICDSS is an administrative database subject to recording bias. However, identification of physical conditions using QICDSS data has shown high validity compared with medical charts. ${ }^{44}$ Our case definitions for mental disorders have been used elsewhere with high external validity. ${ }^{45,46}$ Our classification of common and serious mental disorders is simplified and may not reflect individual clinical realities. However, it has shown population-level validity in previous research. 4,31,32,47 Mental illness status was frozen on Mar. 31, 2014, ignoring new cases or remissions occurring thereafter. This likely affects mostly common mental disorders, and limiting the surveillance period to 1 year reduces misclassification. Our data likely underestimate prevalence of mental disorders, as treatment may be provided by social workers and privately paid psychologists. Although we did not have access to emergency department records, our validated algorithm shows high agreement with emergency department discharge records. ${ }^{33}$ Our analysis did not adjust for potential clustering of visits by hospital, which may be an important factor in explaining frequent visits. We could not assess some potentially confounding variables such as medication use, which is available in the QICDSS only for people aged 65 years and older, or physical activity, dietary habits and other lifestyle factors, which are unavailable for the entire population. Also, we chose not to adjust for use of other types of outpatient care in order to avoid adding collinearity to the statistical model and producing invalid estimates. Effectively, frequent users of the emergency department are generally frequent users of other outpatient services as well; they report receiving more, but less effective and satisfactory care. ${ }^{13,34}$ These factors are thus correlated, and including both could violate the assumptions of a logistic model. We studied only Quebec residents, and thus external generalizability is uncertain, although it likely extends to other Canadian provinces and developed countries.

\section{Conclusion}

Our study shows the potential synergy between physical multimorbidity and mental disorders with respect to frequent visits to the emergency department. More research is needed to understand at-risk populations and test suitable interventions to promote high-quality care for mental illness that have the potential to reduce avoidable visits to the emergency department.

\section{References}

1. Barnett K, Mercer SW, Norbury M, et al. Epidemiology of multimorbidity and implications for health care, research, and medical education: a cross-sectional study. Lancet 2012;380:37-43.

2. Boyd CM, Fortin M. Future of multimorbidity research: how should understanding of multimorbidity inform health system design? Public Health Rev 2010;32:451-74. doi: 10.1007/BF03391611.

3. Katon WJ. Clinical and health services relationships between major depression, depressive symptoms, and general medical illness. Biol Psychiatry 2003;54:216-26.

4. Parks J, Svendsen D, Singer P, et al., editors. Morbidity and mortality in people with serious mental illness. Alexandria (VA): National Association of State Mental Health Program Directors (NASMHPD) Medical Directors Council; 2006.

5. Walker ER, Druss BG. Cumulative burden of comorbid mental disorders, substance use disorders, chronic medical conditions, and poverty on health among adults in the U.S.A. Psychol Health Med 2017;22:727-35.

6. Schmitz N, Wang J, Malla A, et al. Joint effect of depression and chronic conditions on disability: results from a population-based study. Psychosom Med 2007;69:332-8.

7. McCusker J, Tousignant $P$, Borgès Da Silva $R$, et al. Factors predicting patient use of the emergency department: a retrospective cohort study. CMAJ 2012;184:E307-16.

8. Ionescu-Ittu R, McCusker J, Ciampi A, et al. Continuity of primary care and emergency department utilization among elderly people. CMAJ 2007;177:1362-8.

9. Hardie TL, Polek C, Wheeler E, et al. Characterising emergency department high-frequency users in a rural hospital. Emerg Med J 2015;32:21-5.

10. Krieg C, Hudon C, Chouinard M-C, et al. Individual predictors of frequent emergency department use: a scoping review. BMC Health Serv Res 2016;16:594.

11. Payne RA, Abel GA, Guthrie B, et al. The effect of physical multimorbidity, mental health conditions and socioeconomic deprivation on unplanned admissions to hospital: a retrospective cohort study. CMAJ 2013;185:E221-8. 
12. Zulman DM, Pal Chee C, Wagner TH, et al. Multimorbidity and healthcare utilisation among high-cost patients in the US Veterans Affairs Health Care System. BMJ Open 2015;5:e007771.

13. Billings J, Raven MC. Dispelling an urban legend: frequent emergency department users have substantial burden of disease. Health Aff(Millwood) 2013;32:2099-108.

14. Graham K, Cheng J, Bernards S, et al. How much do mental health and substance use/addiction affect use of general medical services? Extent of use, reason for use, and associated costs. Can J Psychiatry 2017;62:48-56.

15. van der Linden MC, van den Brand CL, van der Linden N, et al. Rate, characteristics, and factors associated with high emergency department utilization. Int J Emerg Med 2014;7:9.

16. van Tiel S, Rood PPM, Bertoli-Avella AM, et al. Systematic review of frequent users of emergency departments in non-US hospitals: state of the art. Eur J Emerg Med 2015;22:306-15.

17. Rothman KJ. Epidemiology: an introduction. 2nd ed. Oxford (UK): Oxford University Press; 2012

18. VanderWeele TJ, Knol MJ. A tutorial on interaction. Epidemiol Methods 2014;3:33-72.

19. Blais C, Jean S, Sirois C, et al. Le Système intégré de surveillance des maladies chroniques du Québec (SISMACQ), une approche novatrice. Mal Chron Blessures Can 2014;34:247-56.

20. Gamache P, Hamel D, Pampalon R. L'indice de défavorisation matérielle et sociale: en bref. Montréal: Institut nationale de santé publique du Québec; 2015.

21. Tu K, Campbell NR, Chen Z-L, et al. Accuracy of administrative databases in identifying patients with hypertension. Open Med 2007;1:e18-26.

22. Tu K, Mitiku T, Lee DS, et al. Validation of physician billing and hospitalization data to identify patients with ischemic heart disease using data from the Electronic Medical Record Administrative data Linked Database (EMRALD). Can J Cardiol 2010;26:e225-8.

23. Hux JE, Ivis F, Flintoft V, et al. Diabetes in Ontario: determination of prevalence and incidence using a validated administrative data algorithm. Diabetes Care 2002;25:512-6.

24. Jean S, Candas B, Belzile É, et al. Algorithms can be used to identify fragility fracture cases in physician-claims databases. Osteoporos Int 2012;23:483-501.

25. Ouhoummane N. Impact du diabète sur la mortalité à la suite d'une hospitalisation pour un premier infarctus aigu du myocarde au Québec [thesis]. Québec: Université Laval; 2010.

26. Quan H, Sundararajan V, Halfon $\mathrm{P}$, et al. Coding algorithms for defining comorbidities in ICD-9-CM and ICD-10 administrative data. Med Care 2005;43:1130-9.

27. Quan H, Khan N, Hemmelgarn BR, et al.; Hypertension Outcome and Surveillance Team of the Canadian Hypertension Education Programs. Validation of a case definition to define hypertension using administrative data. Hypertension 2009;54:1423-8.

28. Langton JM, Blanch B, Drew AK, et al. Retrospective studies of end-of-life resource utilization and costs in cancer care using health administrative data: a systematic review. Palliat Med 2014;28:1167-96.

29. Simard M, Sirois C, Candas B. Validation of the combined comorbidity index of Charlson and Elixhauser to predict 30-day mortality across ICD-9 and ICD-10. Med Care 2018;56:441-7.

30. Tonelli M, Wiebe N, Fortin M, et al.; Alberta Kidney Disease Network. Methods for identifying 30 chronic conditions: application to administrative data. BMC Med Inform Decis Mak 2015;15:31.
31. Ouadahi $\mathrm{Y}$, Lesage $\mathrm{A}$, Rodrigue $\mathrm{J}$, et al. Les problèmes de santé mentale sont-ils détectés par les omnipraticiens? Regard sur la perspective des omnipraticiens selon les banques de données administratives. Sante Ment Que 2009;34:161-72. doi: 10.7202/029764ar.

32. Collins E, Tranter S, Irvine F. The physical health of the seriously mentally ill: an overview of the literature: The physical health of the seriously mentally ill. J Psychiatr Ment Health Nurs 2012;19:638-46.

33. Belzile E, Sanche S, McCusker J, et al. A measure of emergency department use based on Quebec's administrative data [technical report]. Montréal: St. Mary's Research Centre; 2011. Available: http://s3.amazonaws.com/stmary-research/ attachments/000/000/048/original/11d7c5871fe5b810091286ef300ffa02 (accessed 2017 Apr. 20).

34. LaCalle E, Rabin E. Frequent users of emergency departments: the myths, the data, and the policy implications. Ann Emerg Med 2010;56:42-8.

35. Pampalon R, Martinez J, Hamel D. Does living in rural areas make a difference for health in Québec? Health Place 2006;12:421-35.

36. Muller $\mathrm{CJ}$, MacLehose RF. Estimating predicted probabilities from logistic regression: different methods correspond to different target populations. Int J Epidemiol 2014;43:962-70.

37. Vu F, Daeppen J-B, Hugli O, et al. Screening of mental health and substance users in frequent users of a general Swiss emergency department. BMC Emerg Med 2015;15:27.

38. McCabe MP, Leas L. A qualitative study of primary health care access, barriers and satisfaction among people with mental illness. Psychol Health Med 2008;13:303-12.

39. Liddy C, Blazkho V, Mill K. Challenges of self-management when living with multiple chronic conditions. Can Fam Physician 2014;60:1123-33.

40. Kisely S, Smith M, Lawrence D, et al. Inequitable access for mentally ill patients to some medically necessary procedures. CMAJ 2007;176:779-84

41. Kenning C, Fisher L, Bee $\mathrm{P}$, et al. Primary care practitioner and patient under standing of the concepts of multimorbidity and self-management: a qualitative study. SAGE Open Med 2013;1:2050312113510001.

42. Lesage A. Heuristic model of depressive disorders as systemic chronic disease. Epidemiol Psychiatr Sci 2015;24:309-11.

43. McEwen BS. Mood disorders and allostatic load. Biol Psychiatry 2003;54:200-7.

44. Lambert L, Blais C, Hamel D, et al. Evaluation of care and surveillance of cardiovascular disease: Can we trust medico-administrative hospital data? Can J Cardiol 2012;28:162-8.

45. Diallo FB, Fombonne É, Kisely S, et al. Prevalence and correlates of autism spectrum disorders in Quebec: Prévalence et corrélats des troubles du spectre de l'autisme au Québec. Can J Psychiatry 2018;63:231-9.

46. Surveillance des troubles mentaux au Québec: prévalence, mortalité et profil d'utilisation des services. Montréal: Institut national de santé publique de Québec; 2012. Available: www.inspq.qc.ca/pdf/publications/1578_SurvTroublesMentauxQc PrevalMortaProfilUtiliSenvices.pdf (accessed 2017 Apr. 19).

47. Albrecht JS, Hirshon JM, Goldberg R, et al. Serious mental illness and acute hospital readmission in diabetic patients. Am J Med Qual 2012;27:503-8.

48. Moe J, Kirkland SW, Rawe E, et al. Effectiveness of interventions to decrease emergency department visits by adult frequent users: a systematic review. Acad Emerg Med 2017;24:40-52.
Competing interests: Bernard Candas is an employee of the Institut national de santé et services sociaux du Québec. No other competing interests were declared.

This article has been peer reviewed.

Affiliations: Département de médecine sociale et préventive (Gaulin, Candas, Sirois), Faculté de médecine, Université Laval, Québec, Que.; Institut national de santé publique du Québec (INSPQ) (Gaulin, Simard, Lesage, Sirois), Montréal, Que.; Institut national d'excellence en santé et services sociaux (INESSS) (Candas), Québec, Que.; Département de psychiatrie (Lesage), Université de Montréal, Montréal, Que.

Contributors: Myles Gaulin conceptualized and designed the study, carried out the analysis, interpreted the data and drafted the initial manuscript. Marc Simard conceptualized and designed the study, contributed to the analysis, interpreted the data and contributed to the initial manuscript. Caroline Sirois and Bernard Candas, conceptualized and designed the study, provided oversight of the analysis, interpreted the data and critically reviewed and revised the manuscript. Alain Lesage contributed to study conception and design, provided oversight of the analysis, interpreted the data and critically reviewed and revised the manuscript. All the authors gave final approval of the version to be published and agreed to accountable for all aspect of the work.

Funding: Caroline Sirois is the recipient of a Junior 1 research award from the Fonds de recherche du Québec - Santé (FRQS) and of a grant from the Centre de recherche sur les soins et les services de première ligne de l'Université Laval.

Data sharing: The authors do not have permission to share the data extracted for this study from the Quebec Integrated Chronic Disease Surveillance System database.

Acknowledgment: The authors thank Valérie Émond, Head of Chronic Disease and Trauma Surveillance at the Institut national de santé publique du Québec, as well as the entire Québec Integrated Chronic Disease Surveillance System team for their valuable assistance during our research.

Accepted: May 23, 2019

Correspondence to: Marc Simard, Marc.Simard@inspq.qc.ca 